\title{
Musculoskeletal ultrasonography bypasses the diagnOSTIC AND RADIOLOGICAL CHALLENGES IN HETEROTOPIC OSSIFICATION
}

Singapore Med J 2014; 55(11): 604 doi: 10.11622/smedj.2014161

Dear Sir,

We take great interest in the recently published article, "Neurogenic heterotopic ossification after a stroke: diagnostic and radiological challenges", by Pek et al. ${ }^{(1)}$ The authors presented a rare case of heterotopic ossification (HO) occurring on the non-hemiplegic side after stroke, and mentioned the radiologic and diagnostic challenges encountered, discussing computed tomography and magnetic resonance imaging. However, the authors did not discuss ultrasonography, which can be used for early detection and differential diagnosis of $\mathrm{HO}$.

Previous studies suggest that bedside ultrasonography can be readily used as the first-line imaging modality for the detection of $\mathrm{HO}$, with several advantages such as having high spatial resolution and no ionising radiation, and is repeatable, widely available, and cheaper than computed tomography and magnetic resonance imaging. ${ }^{(2,3)}$ Ultrasonography has a high specificity - deep venous thrombosis, haematoma, and muscle tears can easily be differentiated from $\mathrm{HO}$ using ultrasonography. Positive findings of $\mathrm{HO}$ can be detected via ultrasonography two weeks after the onset of the symptoms, even before radiological occurrence. Zone phenomenon or cloudy appearance is the typical ultrasonographic finding of $\mathrm{HO} \cdot{ }^{(3)}$ In addition, any vascular or nerve compression can be visualised on ultrasonography. We would thus like to highlight the role ultrasonography can play in the early diagnosis and follow-up of HO.

Yours sincerely,

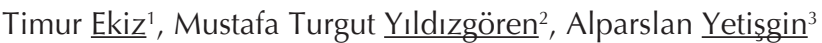

${ }^{1}$ Department of Physical Medicine and Rehabilitation, Ankara Physical Medicine and Rehabilitation Training and Research Hospital, ${ }^{2}$ Department of Physical Medicine and Rehabilitation, Mustafa Kemal University Medical School, ${ }^{3}$ Department of Physical Medicine and Rehabilitation, Şanlıurfa Training and Research Hospital, Turkey. timurekiz@gmail.com

\section{RefERENCES}

1. Pek CH, Lim MC, Yong R, Wong HP. Neurogenic heterotopic ossification after a stroke: diagnostic and radiological challenges. Singapore Med J 2014; 55:e119-22.

2. Falsetti P, Acciai C, Palilla R, et al. Bedside ultrasound in early diagnosis of neurogenic heterotopic ossification in patients with acquired brain injury. Clin Neurol Neurosurg 2011; 113:22-7.

3. Ozçakar L, Carli AB, Tok F, et al. The utility of musculoskeletal ultrasound in rehabilitation settings. Am J Phys Med Rehabil 2013; 92:805-17. 